\title{
Pushing the threshold: how NMDAR antagonists induce homeostasis through protein synthesis to remedy depression.
}

Kimberly F. Raab-Graham ${ }^{1,2,3, \star}$, Emily R. Workman ${ }^{1,2,4}$, Sanjeev Namjoshi ${ }^{1,3}$, and Farr Niere $^{1,2}$

1. Center for Learning and Memory, Department of Neuroscience, Institute of Neuroscience, 2. Waggoner Center for Alcohol and Addiction Research, 3. Institute for Cell and Molecular Biology, University of Texas at Austin, Austin, Texas, 78712. 4. Present Address: U.S. Army Institute of Surgical Research, Burns Injury and Regenerative Medicine Houston, United States

${ }^{*}$ To whom correspondence should be addressed: Kimberly F. Raab-Graham, Center for Learning and Memory, Department of Neuroscience, University of Texas at Austin, 1 University Station C7000, Austin, TX 78712, USA, Tel: (512) 232-0892; Fax: (512) 4758000; E-mail: Kimberly@mail.clm.utexas.edu

Abstract: 237 words

Manuscript: 5179 words

References: 139

Pages: 45

Table: 1

Figures: 3 


\section{Abstract:}

Healthy neurons have an optimal operating range, coded globally by the frequency of action potentials or locally by calcium. The maintenance of this range is governed by homeostatic plasticity. Here, we discuss how new approaches to treat depression alter synaptic activity. These approaches induce the neuron to recruit homeostatic mechanisms to relieve depression. Homeostasis generally implies that the direction of activity necessary to restore the neuron's critical operating range is opposite in direction to its current activity pattern. Unconventional antidepressant therapies-deep brain stimulation and NMDAR antagonists—alter the neuron's "depressed" state by pushing the neuron's current activity in the same direction but to the extreme edge. These therapies rally the intrinsic drive of neurons in the opposite direction, thereby allowing the cell to return to baseline activity, form new synapses, and restore proper communication. In this review, we discuss seminal studies on protein synthesis dependent homeostatic plasticity and their contribution to our understanding of molecular mechanisms underlying the effectiveness of NMDAR antagonists as rapid antidepressants. Rapid antidepressant efficacy is likely to require a cascade of mRNA translational regulation. Emerging evidence suggests that changes in synaptic strength or intrinsic excitability converge on the same protein synthesis pathways, relieving depressive symptoms. Thus, we address the question: Are there multiple homeostatic mechanisms that induce the neuron and neuronal circuits to self-correct to regulate mood in vivo? Targeting alternative ways to induce homeostatic protein synthesis may provide, faster, safer, and longer lasting antidepressants. 


\section{Contents}

1. Introduction: Engaging homeostatic mechanisms with pharmacological intervention to treat Major Depressive Disorder

2. NMDAR antagonism leads to homeostatic plasticity

3. Mammalian Target of Rapamycin (mTOR) serves as a thermostat in NMDAR antagonist-induced homeostatic response

4. Rapid antidepressant efficacy requires distinct stages of neuronal protein synthesis

5. NMDAR antagonists induce structural homeostasis that correlates with antidepressant efficacy

6. Evidence for alternative ways of inducing homeostatic plasticity to remedy depression.

7. Perspectives and Open Questions

8. Conclusions

Acknowledgements

References 


\section{Introduction: Engaging homeostatic mechanisms with pharmacological intervention to treat Major Depressive Disorder}

The idea of using modern medicine to push "out-of-balance" or diseased neurons to their tipping point seems outrageous. However, basic scientists do so on a regular basis. Experimental paradigms that induce long-lasting changes in synaptic efficacy-in one direction-are used to study cellular mechanisms of learning and memory (synaptic plasticity). Sustained extremes in neuronal activity, inherent to synaptic plasticity, eventually cause neurons and neuronal circuits to become unstable (Davis and Goodman, 1998; Pozo and Goda, 2010; Turrigiano and Nelson, 2000).To avoid this problem, healthy neurons adjust their synaptic strength to maintain optimal action potential firing rates. This process is known as homeostatic plasticity and requires dynamic molecular changes (Turrigiano, 2008).

Depression, anxiety disorders, and addiction, result from imbalanced neuronal networks (Figure 1A) (McClung and Nestler, 2008). Such perturbations in neuronal signaling, while severe, may not tip the scale enough for homeostatic mechanisms to kick in. Can modern medicine capitalize on what basic science has taught us about homeostasis? In other words, can pharmacological intervention in vivo push neuronal activity to its limit to induce homeostatic response that will eventually cause neurons and neuronal circuits to self-correct? Studies on rapid antidepressant therapies (i.e. Nmethyl-D-aspartate receptor (NMDAR) antagonists argue yes (Figure 1B-C).

Are new antidepression therapies necessary? 
Major Depressive Disorder (MDD) is a severe neuropathophysiology that will affect up to $17 \%$ of the population at some point during their lifetimes (Zarate et al., 2010). The most common pharmacological therapies, selective serotonin reuptake inhibitors (SSRIs), target the serotonergic system by blocking serotonin uptake. Unfortunately, only $\sim 37 \%$ of individuals afflicted with MDD experience relief from their depressive symptoms with SSRIs (Murrough, 2012). Moreover, with continued use of SSRIs, only 35-50\% will go into remission (Murrough and Charney, 2012; Rush et al., 2006; Trivedi et al., 2008; Trivedi et al., 2006). Thus, finding new effective treatments for MDD is imperative. New therapies, such as rapid antidepressants and deep brain stimulation, are hypothesized to work by engaging network and cellular homeostatic mechanisms. Consequently, these therapies that are revolutionizing depression treatment, are predicted to drive the neurons to self-correct.

\section{What are Rapid Antidepressants?}

Rapid antidepressants are antagonists of NMDARs (Table 1). NMDAR is a ligand and voltage-gated cation channel that is best characterized for its role in shaping synaptic strength during synaptic plasticity (Blanke and VanDongen, 2009). Behavioral assessment has shown that ketamine, Ro 25-6981and other FDA approved NMDAR antagonists have remarkable efficacy in reversing treatment-resistant depression phenotypes. Additionally, NMDAR antagonists increase synaptogenesis, suggesting that increased neuronal communication arises from NMDAR blockade (Ibrahim et al.; Lepack et al., 2015; Li et al., 2010). While Trullas and Skolnick observed 25 years ago that NMDAR antagonists have antidepressant properties in rodents, recent clinical studies on the efficacy of ketamine and other NMDAR antagonists have renewed the 
field's interest in these drugs as potential antidepressants (Skolnick et al., 2009; Zarate et al., 2006). Still, at the molecular level, it is uncertain as to why blocking NMDARs relieves depressive symptoms. This review focuses on the convergence of the clinical application of NMDAR antagonists and the basic science of neuronal homeostasis focusing on protein synthesis-dependent pathways.

\section{NMDAR antagonism leads to homeostatic plasticity}

A neuron employs two forms of homeostatic responses-global and local synaptic scaling — to deal with extreme high or low activity (Turrigiano, 2012). Global synaptic scaling induces a slow, cell-wide compensation in excitatory and inhibitory receptors throughout the soma and dendritic arbor. In contrast, local synaptic scaling occurs within hours as a response to local activity fluctuations, allowing dendrites or groups of synapses to restore operation at an optimal range (Queenan et al., 2012). NMDAR subunit composition underlies the homeostatic mechanism of Metaplasticity

Metaplasticity is a form of homeostasis describing how cells or circuits reset their baseline activity levels in response to their previous activity (Abraham et al., 2001). Metaplasticity has been studied mostly at the circuit level, albeit it has been reported to occur at a single synapse (Lee et al., 2010a). For example, in seminal studies that deprive rodents of light during a critical period of visual developmental, the absence of visual input alters the threshold for synaptic plasticity in the forms of long-term potentiation (LTP) and long-term depression (LTD) (Kirkwood et al., 1996; Philpot et al., 2003). At the molecular level, light deprivation induces cell-wide forms of synaptic 
scaling by upregulating excitatory receptors and downregulating inhibitory receptors. Such a shift in the ratio of excitatory and inhibitory inputs will favor excitation and is consistent with a reduced threshold to induce LTP (Turrigiano, 2012). Interestingly, upon a short exposure to light, causing cortical activity to rise, more excitatory synaptic input is required to induce LTP (Philpot et al., 2003). These experiments, as well as many that have come before and after, serve as the basis for metaplasticity (Bear, 1995).

At the molecular level, changes in NMDAR subunit composition that regulate calcium dynamics likewise support metaplasticity (Yashiro and Philpot, 2008). NMDARs are obligate heteromultimers consisting of an NR1 subunit in combination with NR2A-D and NR3A-B (Glasgow et al., 2015). NR2A and B are the most critical subunits in setting the membrane threshold (Yashiro and Philpot, 2008). NR2B-containing NMDARs are slower to deactivate and thus carry more calcium per unit current relative to NR2A-containing receptors (Glasgow et al., 2015; Sobczyk et al., 2005) . A decrease in the NR2A/2B ratio, an adjustment that appears to be seemingly modest in nature, significantly slides the threshold to favor LTP. As expected, NR2B-containing channels are upregulated relative to NR2A in the dark; and upon activation, allow for greater influx of calcium in spines (Yashiro and Philpot, 2008). Thus, one would predict that blocking NR2B activity under conditions of reduced cortical activity would provide the biggest push toward silencing synaptic activity. Furthermore, such a push may be sufficient to engage alternative homeostatic mechanisms to return the neuron back to an optimal operating range. 


\section{Mammalian Target of Rapamycin (mTOR) serves as a thermostat in NMDAR antagonist-induced homeostatic response}

mTOR senses the functional, operating range of a neuron

How does one identify if a neuron is "out-of-range"? Is there a molecular marker whose activity level gauges the general health of a neuron? In MDD, it has been suggested that mTOR activity levels may serve as a molecular thermostat as it can gauge the efficacy of antidepressant drugs (Zarate et al., 2013). mTOR is a serine/threonine kinase that controls protein synthesis, cell growth and metabolism by sensing the levels of nutrients, growth factors, cellular energy, and stress. mTOR is conserved from yeast to human, signifying its critical importance in cellular homeostasis. mTOR consists of two complexes, mTORC1 and C2. mTORC1 regulates protein synthesis through phosphorylation of two proteins that regulate mRNA translation-eukaryotic initiation factor 4 binding protein (elF4BP) and ribosomal S6 kinase (Hay and Sonenberg, 2004). In the brain, mTOR mediates dendritic protein synthesis, critical for synaptic plasticity and memory consolidation (Graber et al., 2013).

In many diseases, mTORC1 is often overactive or underactive, consistent with a neuron operating outside its optimal range. For example, in epilepsy, Alzheimer's disease, and autism spectrum disorders-including Fragile X Syndrome and Tuberous Sclerosis Complex-mTORC1 signaling is excessive (Crino, 2015; Gross et al., 2010; Pei and Hugon, 2008; Sahin, 2012; Santini and Klann, 2011; Sharma et al., 2010; Sosanya et al., 2014; Spilman et al., 2010; Zeng et al., 2009; Zeng et al., 2011). Furthermore in MDD and Parkinson's disease, mTORC1 signaling is reduced (Fragkouli and Doxakis, 2014; Jernigan et al., 2011). It is currently unknown how mTORC1 gets 
stuck and fails to return to basal levels in these diseases. What can be done to "unstick" mTOR activity, allowing it to return to basal levels? Insights from NMDAR antagonists used for treating MDD may offer an answer. Several labs have shown that mTORC1 activity increases with a single treatment of NMDAR antagonists in vivo. The increase in mTORC1 is required for the antidepressant efficacy of NMDAR antagonists ( $\mathrm{Li}$ et al., 2010; Workman et al., 2013). In the brain, where the circuitry is intact and the release of neurotransmitters is difficult to control, deciphering how NMDAR blockade increases mTOR activity is challenging. Utilizing a simplified model of cultured hippocampal neurons, where one has tight control over the activation of neurotransmitter receptors, blockade of NMDARs with (2R)-amino-5-phosphonovaleric acid (AP5) reduces basal mTOR activity (Workman et al., 2013). These results indeed suggest that reducing NMDAR signaling pushes mTORC1 activity levels down and would be predicted to induce homeostasis (Figure 1). However as mTORC1 activity remains low, the trigger for the cell to push back and return mTORC1 activity to control levels is absent in these cultures. Collectively, these data provide the first hint that an extrinsic factor, such as a neurotransmitter, is necessary to restore mTORC1 activity to normal basal levels. $N M D A R$ activity at rest shapes the ability of metabotropic $G A B A_{B} R$ signaling to turn mTORC1 activity up.

What turns mTOR activity on with NMDAR blockade? One clue came from studies showing that NMDARs and $\gamma$-aminobutyric acid $B$ receptors $\left(G A B A_{B} R\right)$, that are metabotropic G-protein-coupled receptor, extensively interact in a feedback loop (Guetg et al., 2010; Terunuma et al., 2010; Workman et al., 2013). GABA is considered as the major inhibitory neurotransmitter in the brain (Jembrek and Vlainic, 2015). Under normal 
physiological conditions, $\mathrm{GABA}_{\mathrm{B}} \mathrm{Rs}$ inhibit neuronal activity through pre- and postsynaptic mechanisms. Postsynaptically, $\mathrm{GABA}_{B} \mathrm{Rs}$ mediate the slow inhibitory postsynaptic potentials via the activation of postsynaptic, G-protein-regulated, inwardly rectifying potassium (GIRK) channels (Padgett and Slesinger). Stimulating NMDARs in cultured hippocampal neurons leads to endocytosis of GABABRs (Guetg et al., 2010; Terunuma et al., 2010). Likewise, blocking NMDAR signaling in vitro increases the dendritic surface expression of GABA ${ }_{B} R s$ (Workman et al., 2013). This reciprocal relationship between synaptic activity and $G A B A_{B} R$ surface expression, at first glance, would appear to provide positive feedback—less inhibition with synaptic stimulation and more inhibition with reduced synaptic activity. Surprisingly, NMDAR blockade causes $\mathrm{GABA}_{B} R$ function to shift from signaling that opens GIRK channels to signaling that increases dendritic $\mathrm{Ca}^{2+}$ requiring L-type $\mathrm{Ca}^{2+}$ channel activity (Workman et al., 2013). This increase in $\mathrm{Ca}^{2+}$, in turn, activates $\mathrm{mTORC} 1$ in primary apical dendrites that are enriched in GABAergic synapses (Megias et al., 2001; Workman et al., 2013). Moreover, GABABR signaling through mTORC1 promotes the synthesis of the brain derived neurotropic factor (BDNF), which is required for new synapse formation with rapid antidepressants (Figure 2) (Li et al., 2010; Workman et al., 2013). These results emphasize that restoring neuronal communication leads to the sustained antidepressive efficacy of NMDAR antagonists (Li et al., 2010; Li et al., 2011; Liu et al., 2012).

\section{Rapid antidepressant efficacy requires distinct stages of neuronal protein synthesis}

Evoked versus miniature NMDAR currents 
One perplexing concept regarding the effectiveness of NMDAR antagonists as rapid antidepressant is the requirement that the membrane be depolarized for NMDARs to open. NMDARs require the binding of two neurotransmitters, glutamate and glycine. Even in the presence of these molecules the channel remains closed due to $\mathrm{Mg}^{2+}$ blocking the ion-conducting pathway. Depolarization of the membrane dislodges $\mathrm{Mg}^{2+}$, and facilitates the movement of cations, particularly $\mathrm{Ca}^{2+}$, in and out of the cell (Burnashev et al., 1992). Considering the strict biophysical properties of the channel, one would predict that NMDAR antagonists quiet active neurons and neuronal circuits. However, some studies suggest that the $\mathrm{Mg}^{2+}$ block of NMDARs is partial at the resting membrane potential (Reese and Kavalali, 2015). Fortunately, since NMDAR antagonists come in many flavors, pharmacological approaches can dissect NMDAR resting current blockade from evoked and total NMDAR blockade. For example, MK-801, which selectively blocks open NMDARs, and memantine, only blocks NMDARs when $\mathrm{Mg}^{2+}$ is dispelled from the pore conducting pathway, are widely used. It is generally considered that MK-801 blocks both evoked and resting NMDAR currents, whereas memantine only blocks NMDARs engaged in firing Remarkably, rodents treated with MK-801 display improvement on behavioral despairs, while with memantine they do not (Autry et al., 2011; Gideons et al., 2014). Thus, NMDAR antagonists that are used as rapid antidepressants (e.g. MK-801) are effective at reducing the activity of neurons engaged in firing, as well as a population of NMDARs that are open at rest via spontaneous activity.

NMDAR blockade-induced translation initiates two phases of antidepressant efficacy 
Studies suggest that antidepressant efficacy requires two phases-induction and sustained. While it is clear that mTORC1-dependent protein synthesis is required for the long-lasting effects of rapid antidepressants, the molecular changes that initiate the process remain unclear. Does the initiation phase require protein synthesis? Work on local homeostatic synaptic scaling demonstrates that acute blockade of spontaneous NMDAR activity increases the miniature excitatory synaptic current (mEPSC) mediated by the glutamate receptor that contains $\alpha$-amino-3-hydroxy-5-methyl-4isoxazolepropionic acid (AMPA) 1 subtype (GluA1). Such AMPAR-mediated synaptic scaling requires de novo dendritic protein synthesis of GluA1 (Sutton et al., 2006).

Notably, several groups have observed increased expression of GluA1 with administration of NMDAR antagonists in vivo (Autry et al., 2011; Li et al., 2010; Nosyreva et al., 2013; Workman et al., 2013). A separate set of studies have also demonstrated that blocking spontaneous NMDAR activity increases evoked AMPARmediated synaptic potentiation in the CA1 region of hippocampal slices. This form of potentiation was sustained and further amplified an hour after the antagonist had been washed away (Nosyreva et al., 2013). Interestingly in a BDNF knockout mouse, the initial synaptic potentiation due to NMDAR antagonists was present and similar to wildtype slices; however, the sustained potentiation was absent. In contrast, the inclusion of a protein synthesis inhibitor blocked the early and sustained potentiation induced by NMDAR blockade, indicating a requirement for protein synthesis in both plasticities (Nosyreva et al., 2013). These results confirm the necessity of BDNF for the long-lasting effects on synaptic potentiation due to NMDAR blockade and perhaps hint at a separate requirement for protein synthesis for the initial potentiation phase. 
If $\mathrm{mTORC} 1$ activity mediates translation of mRNAs that are required for the sustained antidepressant effects of NMDAR antagonists, what mediates protein synthesis in the initiation phase? Schuman and colleagues proposed that $\mathrm{Ca}^{2+}$ entry through open NMDARs promotes the kinase activity of the eukaryotic elongation factor 2 kinase (eEF2K), which inhibits eEF2-an elongation factor that promotes global mRNA translation. As they had predicted, NMDAR blockade with AP5 in the presence of tetrodotoxin (TTX), which inhibits action potential, reduced $\mathrm{Ca}^{2+}$ entry, inactivated eEF2K, and increased local protein synthesis. These results led the authors to conclude that NMDAR-mediated mEPSCs inhibit local protein synthesis (Sutton et al., 2006; Sutton and Schuman, 2006; Sutton et al., 2004). These studies, for the first time, assigned a function to spontaneous release and mEPSCs, as a critical regulator of homeostatic protein synthesis (Sutton et al., 2004). In light of MDD, do NMDARmediated mEPSCs occur more often or have a greater impact in "depressed" neurons or neuronal circuits? There is no direct experimental evidence that addresses this question. However, work on rapid antidepressants demonstrates that eEF2-dependent translation is upregulated with NMDAR antagonists in vivo. Furthermore, NMDARantagonist-induced antidepressant response can be bypassed completely by treating rodents with drugs that directly activate eEF2 (Autry et al., 2011).

\section{NMDAR antagonists induce structural homeostasis that correlates with antidepressant efficacy}

One of the most striking effects of rapid antidepressants is increased spine density (Ohgi et al., 2015). Dendritic spines are the primary location of excitatory 
synapses in the adult brain. Spine shape, size, and number vary over the normal lifetime of an individual, and many neuropathologies display atypical spine distribution, shape, and number (Bourne and Harris, 2008). Structural homeostasis is defined by neuronal architecture changes in response to long-term fluctuations in activity (Yin and Yuan, 2014). Over the years, sensory paradigms that prompt homeostatic plasticity also induce morphological changes in spines (Butz et al., 2009; Keck et al., 2011). For example, sensory deprivation results in enlarged spine heads and increased postsynaptic AMPAR expression (Keck et al., 2013; Wallace and Bear, 2004). Moreover, whisker trimming paradigms that reduce sensory inputs to the cortex decreased spine elimination (Zuo et al., 2005).

In 1999, Kirov and Harris found that blocking NMDARs in an acute hippocampal slice preparation significantly increased the spine density in dendrites (Kirov and Harris, 1999). Duman and colleagues, a decade later, also reported that NMDAR antagonism increased dendritic spines in vivo by using mice that sparsely expressed yellow fluorescent protein in the prefrontal cortex (Li et al., 2010; Li et al., 2011). With new synapse formation one would expect increased pre- to postsynaptic signaling. As predicted, mEPSC frequency in layer II/III cortical neurons increased 24 hours postrapid antidepressant injection (ketamine or Ro 25-6981) (Miller et al., 2014). mTOR mediates NMDAR antagonist-induced spine formation

mTOR activity increases spine density. In neurons with hyperactive mTOR signaling, elevated spine number can be reduced with the mTORC1 inhibitor rapamycin (Tavazoie et al., 2005). It has been suggested that mTORC1-dependent protein synthesis is required for new spine formation and may be the key link for remission from 
depression (Li et al., 2010; Li et al., 2011). In support of this view, direct rapamycin infusion into the prefrontal cortex prevents the ketamine-induced increase in spine number (Li et al., 2010; Li et al., 2011). Of note, BDNF, which is translated via eEF2 and mTORC1, is necessary for the increased expression, maturation and stability of spines (Bennett and Lagopoulos, 2014). In light of how BDNF is translated, speculations abound that BDNF synthesis is required for the expression of the early and late phases of NMDAR antagonist-mediated antidepressant response, whereby the "early" synthesized BDNF is secreted to act upon postsynaptic TrkB receptors that bind BDNF with high affinity (Autry et al., 2011). Upon BDNF binding, TrkB signals cascade to turn mTOR on (Kavalali and Monteggia, 2012, 2015; Takei et al., 2004). BDNF secretion from the postsynaptic neuron is likely to require L-type calcium activity, perhaps through the activation of GABABRs (Lepack et al., 2015; Workman et al., 2013). Further work is needed to test this hypothesis and to identify the intermediate events that lead to new synapse formation. In spite of incomplete mechanistic details, these data suggest that altering neuronal activity with natural stimuli such as light, experimentally with whisker trimming, or pharmacologically with NMDAR antagonists promotes changes in spine shape, size and density to maintain homeostasis.

\section{Evidence for alternative ways of inducing homeostatic plasticity to remedy depression}

Intrinsic Excitability 
If NMDAR antagonists exert their action by lowering synaptic activity to engage homeostatic mechanisms, then directly altering ion channel function or density (intrinsic excitability) of the dendritic membrane may serve the same function as NMDAR antagonism. For example, knockdown of the HCN1 channel produces an antidepressant behavioral phenotype and increases mTOR and BDNF, two molecular mediators of rapid antidepressant efficacy (Kim et al., 2012). While ketamine is best known for its ability to block NMDARs, it has been shown to also block HCN channels (Chen et al., 2009). Moreover, as mentioned above, switches in receptor-channel signaling are involved in formation and reversal of depressive symptoms. Specifically upon NMDAR antagonism, GABABR signaling to GIRK channels decreases while L-type channel activity increases. This switch in turn enhances mTOR activity and BDNF expression (Workman et al., 2013). Blocking the decoupling of GABA $R$ from GIRK in the presence of NMDAR antagonists restores $\mathrm{GABA}_{B} \mathrm{R}$-mediated hyperpolarization and prevents rapid antidepressant efficacy in vivo (Workman et al., 2015). Interestingly, sleep deprivation also mediates a rapid antidepressant effect (McClung, 2007). In fruit flies, a screen designed to find mutants with a short sleeping phenotype identified the shaker locus (Kv1) (Cirelli et al., 2005), a channel whose expression is repressed by mTORC1 activity (Niere et al., 2016; Raab-Graham et al., 2006; Sosanya et al., 2015a; Sosanya et al., 2015b; Sosanya et al., 2013). It will be interesting if like HCN, reduced levels of Kv1.1 feedback to increase mTORC1/BDNF signaling resulting in antidepressant behaviors. All in all, these findings suggest that changes in intrinsic excitability can regulate the mTOR/BDNF antidepressant pathway.

Regulation of Autophagy 
Aberrant autophagy has been suggested to underlie depression (Abelaira et al., 2014). Autophagy is triggered when the cell is deprived of nutrients or placed in stressed conditions and serves to recycle organelles, clear protein aggregates, and eliminate non-essential macromolecules in order to aid in cell survival. In certain cases, cell signaling events that induce autophagy eventually lead to apoptosis (Marino et al., 2014). Tissue studies in human and animal models have shown that depression is characterized by the loss of neural and glial cells due to chronic stress (Banasr and Duman, 2008; Krishnan and Nestler, 2008; Pittenger and Duman, 2008). Various stress paradigms in rats have been shown to upregulate levels of pro-apoptotic proteins that are released through mitochondrial outer membrane permeablization as well as the release of caspase 3 (Bachis et al., 2008; Kosten et al., 2008). Furthermore, a transcriptome-wide profile of post-mortem human prefrontal cortex brain tissue from 14 pairs of subjects analyzed by microarray revealed the over-expression of apoptosis factors and inflammatory cytokines (Shelton et al., 2011). Notably, antidepressants have been shown to upregulate levels of anti-apoptotic proteins, particularly members of the Bcl-2 family involved in the suppression of mitochondrial outer membrane permeabilization, a key step in the intrinsic apoptosis pathway (McKernan et al., 2009).

mTOR is known to control the homeostasis between cell growth (synthesis of new molecules) and autophagy (breakdown of current cell structures and macromolecules). mTOR is a negative regulator of autophagy but its mechanism of control is poorly understood. mTOR phosphorylation of ULK1 prevents activation of the ULK1 complex, a regulator of autophagy and inducer of apoptosis (Ganley et al., 2009; Jung et al., 2009; Lee and Tournier, 2011; Mukhopadhyay et al., 2015). Importantly, a 
reduction in both phosphorylation and expression of components of the mTOR signaling pathway has been observed in a postmortem examination of prefrontal cortex tissue obtained from depressed subjects in a series of studies. These proteins include NR2A, NR2B, mGluR5, PSD-95 as well as mTOR and its downstream targets involved in the control of translation p70SK6, elF4E, p-elF4E, elF4B, and p-elF4B (Deschwanden et al., 2011; Feyissa et al., 2009; Jernigan et al., 2011). All of this suggests an important role for mTOR in the homeostatic balance between autophagy and protein synthesis that may be relevant in the context of depression.

Finally, the NMDAR antagonists, 3-methyladenine (3-MA) and Ro-25-6981, have been shown to suppress the induction of autophagy and neuronal cell death (Bigford et al., 2009; Sadasivan et al., 2010; Xin et al., 2011). Bigford and colleagues demonstrated that Ro-25-6981 blocked the induction of autophagy and lowered the levels of autophagic proteins both in vitro and in vivo. This and previously discussed work suggest the possibility that the Ro-25-6981-mediated repression of NR2B signaling may by neuroprotective through the mTOR pathway. Thus, mTOR may be uniquely positioned (1) to promote the growth of new spines, (2) to regenerate dendritic architecture through protein synthesis, and (3) to suppress autophagy-mediated apoptosis in neurons injured by chronic stress (Jia and Le, 2015). Future studies will be needed to determine the manner in which NR2B-specific antagonists are able to trigger these effects.

\section{Perspectives and Open Questions:}


Insight into depression and antidepressant therapies through the identification of proteins synthesized when mTORC1 is inhibited

Are there other ways to coax the compromised or diseased neuron to self-correct? Clues may come from recent work that examines dendritic protein synthesis in the presence of the mTORC1 inhibitor rapamycin in vivo (Niere et al., 2015). While the role of mTORC1 activity to promote translation of mRNAs is grounded in its established function of phosphorylating elF4BP and ribosomal S6 kinase (Hay and Sonenberg, 2004), a few studies suggest a separate and likely just as important role for mTORC1 activity in repressing mRNA translation of specific transcripts (Niere et al., 2015; RaabGraham et al., 2006; Sosanya et al., 2013). Interestingly, Niere et al., using the unbiased approach of mass spectrometry, demonstrates that the number of proteins that increase at the synapse with mTORC1 inhibition is approximately equal in number to those whose expression is reduced (Niere et al., 2015). Is it possible that some of these mRNAs are homeostatic in nature, and that the proteins they encode may predispose the neuron to turn mTORC1 back on? Notably, some of the proteins that are synthesized with brief mTORC1 inhibition overlap with proteins previously associated with depression and antidepressant properties (Figure 3A-C (Aragam et al., 2011; De Vry et al., 2016; Dekker et al., 2012; Dlugos et al., 2009; Fatemi et al., 2001; Galeotti and Ghelardini, 2011; Gatt et al., 2015; Gray et al., 2015; Lee et al., 2010b; Liu et al., 2015; Luo et al., 2010; Ogawa and Kunugi, 2015; Ray et al., 2014; Rietschel et al., 2010; Sakaida et al., 2013; Shyn et al., 2011; Skoog et al., 2015; Stachowicz et al., 2015; Tadic et al., 2007; Unschuld et al., 2009; Wagner et al., 2015; Yoshimasu et al., 2015)). For example, Homer 1a was found to be upregulated in several paradigms of 
antidepression therapy including sleep deprivation, electroconvulsive shock, ketamine, imipramine, and fluoxetine (Serchov et al., 2015). Moreover, the Homer1 knockout mouse displays phenotypes consistent with anxiety and depression (Szumlinski et al., 2005). To date, it is unclear as to what protein synthesis pathways and translation factors are utilized to translate these homeostatic mRNAs. One would predict that eEF2 is involved but may not be the only factor. Notably, eEF2 is a protein whose expression is differentially regulated by mTORC1 activity, in a subcellular specific manner (Figure 3c). Is synthesis of eEF2 protein required to turn mTORC1 activity on with NMDAR blockade (Figure 2)? Such a result would suggest that additional translational mechanisms upstream of eEF2 are required for antidepressant efficacy. Nevertheless, coordinated stages of protein synthesis utilizing different translational mechanisms such as eEF2 and mTORC1 are required for rapid antidepressant efficacy, and mTORC1dependent translation of BDNF is critical for the sustained effects of NMDAR antagonists (Lepack et al., 2015).

The unexplored role of RNA-binding proteins in rapid antidepression therapy

Targeting new protein synthesis pathways as a means to treat depression is a relatively new idea. As noted above, protein synthesis of specific proteins is orchestrated to mediate short- and long-term effects. Spatial accumulation of mRNAs in dendrites is widely believed to be a mechanism that regulates temporal gene expression. Cis-acting elements such as noncoding RNAs and RNA binding proteins (RBP) reversibly bind to the mRNA and ensure that the message is made into protein only when needed (Fernandez-Moya et al., 2014).To date, little work has been done to determine the role of RNA binding factors in antidepression efficacy. Considering the 
importance of new synaptic connections, RBPs that regulate synapse structure and function are likely to be important for long-lasting antidepressant effects with NMDAR antagonism. Here we will highlight some of the RBPs that are critical for new synapse formation and synaptic scaling.

NMDAR-mediated RNA granule formation: mRNA-silencing foci are RNA granules that contain silenced mRNAs and RBPs that repress translation. Distinct mRNA-silencing foci are formed and dispersed with different forms of synaptic plasticity (Thomas et al., 2014). One particular foci that forms with NMDAR stimulation is the synaptic XRN1 bodies (SX-bodies). While XRN1 is an RBP that is best known for its role in mRNA decay, SX-bodies lack decapping activity and therefore serve to sequester mRNAs (Luchelli et al., 2015). Since these bodies increase upon NMDAR stimulation, it is interesting to ask, what happens to SX-bodies with NMDAR antagonism? Moreover, are the sequestered mRNAs needed for the induction of rapid antidepressant efficacy? mRNA trafficking: A network of RBPs have been implicated in dendritic and synapse morphology. Remarkably, there is little functional redundancy among them. A single knockdown or a mutation in any one RBP disrupts translational regulation of its target mRNAs resulting in dendritic/spine defects. Some of the most compelling data for the importance of RBPs in synapse formation is the knockdown of the RBPs that affect mRNA trafficking (Doyle and Kiebler, 2011). The Staufen proteins are best known for their role in mRNA trafficking into the dendrites and are required for synaptic plasticity (Tang et al., 2001). Knockdown of Stau2 results in $40 \%$ fewer mRNAs in dendrites that are retained in the soma. Moreover, Stau2-knockdown neurons show a significant reduction in synapse number (Goetze et al., 2006). Many depression studies have 
examined total mRNA expression; however synaptic changes in mRNA levels may be obscured. To the best of our knowledge, none have examined synaptic mRNA levels. Future studies regarding RBP-mediated mRNA trafficking deficits with MDD and with rapid antidepressant treatment are needed.

Dendrite and Spine Morphology: Neurodegenerative diseases with synaptic deficiencies may serve as a clue as to which RBPs may be required for new synapse formation with rapid antidepressants. For example, mutations in two nuclear proteins TAR DNAbinding protein 43 (TDP-43) and fused in sarcoma (FUS) are associated with frontotemporal dementia and amyotrophic lateral sclerosis (ALS). Newly discovered roles for TDP-43 and FUS in dendritic branching and synapse formation, respectively, are emerging (Lu et al., 2009; Sephton et al., 2014). For example, FUS accumulates in dendritic spines to regulate morphology upon mGluR5 stimulation (Fujii and Takumi, 2005). Mutations in FUS result in reduced dendritic branching and spine maturation (Sephton et al., 2014). One might predict that even modest changes in the expression or subcellular localization of TDP-43 and FUS may contribute to the observed synaptic dysfunction, synapse loss, and neuronal atrophy in MDD.

Synaptic Scaling: Two RBPs have been implicated in homeostatic synaptic scaling, the retinoic acid receptor (RAR) $\alpha$ and fragile $\mathrm{X}$ mental retardation protein (FMRP). Both RBPs repress translation of their target mRNAs. During synaptic scaling the increase in GluA1 synthesis arises from the upstream intracellular synthesis of retinoic acid (RA), which in turn, causes dissociation of RARa from GluA1 mRNA, allowing it to be translated (Aoto et al., 2008). Interestingly, Soden and Chen demonstrated that AMPAR-mediated synaptic scaling is absent in CA1 hippocampal neurons of Fmr1 
knockout mouse. Moreover, RA-induced mRNA translation of GluA1, GluA2, and eEF2 observed in hippocampal neurons isolated from wildtype mice does not occur in Fmr1 knockout neurons (Soden and Chen, 2010). How FMRP regulates RA-induced synaptic scaling is still an open question. Furthermore, it is unknown whether FMRP- and RAmediated mRNA translation is required for the rapid antidepressant efficacy induced by NMDAR antagonists.

The RBPs discussed here is a representative sample of RBPs that may be essential to restore proper communication between neurons that will relieve depressive symptoms. Many more are likely to be required. Future work examining the roles of RBPs with NMDAR antagonists is therefore crucial. Moreover, targeting specific RBPs may be critical in revealing more specific therapies for MDD.

\section{Conclusion}

Rapid antidepressants activate local homeostatic processes. The efficacy of these drugs relies on their ability to engage homeostatic mechanisms that trigger protein synthesis pathways. Interestingly the antidepressant efficacy remains long after the drug has left the patient's system (Abdallah et al., 2015). The acute dose of NMDAR antagonists engages numerous synaptic mechanisms that produce a sustained and lasting increase in synaptic connections that require protein synthesis. Perhaps these new synapses can reestablish an activity state in the brain that remediates a depressed system. Utilizing native mechanisms of homeostasis, rapid antidepressants offer a novel treatment that may have many applications outside of MDD. 


\section{Acknowledgements}

This study was supported by the National Science Foundation IOS 1026527 and IOS 1355158 (KRG), Postdoctoral Research Fellowship in Biology DBI-1306528 (FN); a NIH-NIAAA pilot grant provided by the Integrated Neuroscience Initiative for Alcoholism (KRG); Department of Defense, United States Army Medical Research and Materiel Command USAMRMC Award W81XWH-14-1-0061 (KRG).

Authors Contributions: KRG, ERW, SN and FN wrote and edited the manuscript. ERW prepared Figure 1 and SN prepared Figure 2 and 3. SN and FN prepared Table 1.

\section{References}

Abdallah, C.G., Sanacora, G., Duman, R.S., and Krystal, J.H. (2015). Ketamine and rapid-acting antidepressants: a window into a new neurobiology for mood disorder therapeutics. Annu Rev Med 66, 509-523.

Abelaira, H.M., Reus, G.Z., Neotti, M.V., and Quevedo, J. (2014). The role of mTOR in depression and antidepressant responses. Life Sci 101, 10-14.

Abraham, M.T., Kuriakose, M.A., Sacks, P.G., Yee, H., Chiriboga, L., Bearer, E.L., and Delacure, M.D. (2001). Motility-related proteins as markers for head and neck squamous cell cancer. Laryngoscope 111, 1285-1289. 
Aoto, J., Nam, C.I., Poon, M.M., Ting, P., and Chen, L. (2008). Synaptic signaling by alltrans retinoic acid in homeostatic synaptic plasticity. Neuron 60, 308-320.

Aragam, N., Wang, K.S., and Pan, Y. (2011). Genome-wide association analysis of gender differences in major depressive disorder in the Netherlands NESDA and NTR population-based samples. J Affect Disord 133, 516-521.

Autry, A.E., Adachi, M., Nosyreva, E., Na, E.S., Los, M.F., Cheng, P.F., Kavalali, E.T., and Monteggia, L.M. (2011). NMDA receptor blockade at rest triggers rapid behavioural antidepressant responses. Nature 475, 91-95.

Bachis, A., Cruz, M.I., Nosheny, R.L., and Mocchetti, I. (2008). Chronic unpredictable stress promotes neuronal apoptosis in the cerebral cortex. Neurosci Lett 442, 104-108. Banasr, M., and Duman, R.S. (2008). Glial loss in the prefrontal cortex is sufficient to induce depressive-like behaviors. Biol Psychiatry 64, 863-870.

Bear, M.F. (1995). Mechanism for a sliding synaptic modification threshold. Neuron 15, $1-4$.

Bennett, M.R., and Lagopoulos, J. (2014). Stress and trauma: BDNF control of dendritic-spine formation and regression. Progress in neurobiology 112, 80-99. Bigford, G.E., Alonso, O.F., Dietrich, D., and Keane, R.W. (2009). A novel protein complex in membrane rafts linking the NR2B glutamate receptor and autophagy is disrupted following traumatic brain injury. J Neurotrauma 26, 703-720.

Blanke, M.L., and VanDongen, A.M.J. (2009). Activation Mechanisms of the NMDA Receptor. In Biology of the NMDA Receptor, A.M. Van Dongen, ed. (Boca Raton (FL)). Bourne, J.N., and Harris, K.M. (2008). Balancing structure and function at hippocampal dendritic spines. Annual review of neuroscience 31, 47-67. 
Burnashev, N., Schoepfer, R., Monyer, H., Ruppersberg, J.P., Gunther, W., Seeburg, P.H., and Sakmann, B. (1992). Control by asparagine residues of calcium permeability and magnesium blockade in the NMDA receptor. Science 257, 1415-1419.

Butz, M., Worgotter, F., and van Ooyen, A. (2009). Activity-dependent structural plasticity. Brain research reviews 60, 287-305.

Chen, X., Shu, S., and Bayliss, D.A. (2009). HCN1 channel subunits are a molecular substrate for hypnotic actions of ketamine. The Journal of neuroscience : the official journal of the Society for Neuroscience 29, 600-609.

Cirelli, C., Bushey, D., Hill, S., Huber, R., Kreber, R., Ganetzky, B., and Tononi, G. (2005). Reduced sleep in Drosophila Shaker mutants. Nature 434, 1087-1092.

Crino, P.B. (2015). mTOR Signaling in Epilepsy: Insights from Malformations of Cortical Development. Cold Spring Harb Perspect Med 5.

Davis, G.W., and Goodman, C.S. (1998). Genetic analysis of synaptic development and plasticity: homeostatic regulation of synaptic efficacy. Curr Opin Neurobiol 8, 149-156.

De Vry, J., Vanmierlo, T., Martinez-Martinez, P., Losen, M., Temel, Y., Boere, J., Kenis, G., Steckler, T., Steinbusch, H.W., Baets, M.D., et al. (2016). TrkB in the hippocampus and nucleus accumbens differentially modulates depression-like behavior in mice.

Behav Brain Res 296, 15-25.

Dekker, M.J., Tiemeier, H., Luijendijk, H.J., Kuningas, M., Hofman, A., de Jong, F.H., Stewart, P.M., Koper, J.W., and Lamberts, S.W. (2012). The effect of common genetic variation in 11beta-hydroxysteroid dehydrogenase type 1 on hypothalamic-pituitaryadrenal axis activity and incident depression. J Clin Endocrinol Metab 97, E233-237. 
Deschwanden, A., Karolewicz, B., Feyissa, A.M., Treyer, V., Ametamey, S.M., Johayem, A., Burger, C., Auberson, Y.P., Sovago, J., Stockmeier, C.A., et al. (2011). Reduced metabotropic glutamate receptor 5 density in major depression determined by [(11)C]ABP688 PET and postmortem study. Am J Psychiatry 168, 727-734.

Dlugos, A.M., Palmer, A.A., and de Wit, H. (2009). Negative emotionality: monoamine oxidase B gene variants modulate personality traits in healthy humans. J Neural Transm (Vienna) 116, 1323-1334.

Doyle, M., and Kiebler, M.A. (2011). Mechanisms of dendritic mRNA transport and its role in synaptic tagging. EMBO J 30, 3540-3552.

Fatemi, S.H., Earle, J.A., Stary, J.M., Lee, S., and Sedgewick, J. (2001). Altered levels of the synaptosomal associated protein SNAP-25 in hippocampus of subjects with mood disorders and schizophrenia. Neuroreport 12, 3257-3262.

Fernandez-Moya, S.M., Bauer, K.E., and Kiebler, M.A. (2014). Meet the players: local translation at the synapse. Front Mol Neurosci 7, 84.

Feyissa, A.M., Chandran, A., Stockmeier, C.A., and Karolewicz, B. (2009). Reduced levels of NR2A and NR2B subunits of NMDA receptor and PSD-95 in the prefrontal cortex in major depression. Prog Neuropsychopharmacol Biol Psychiatry 33, 70-75. Fragkouli, A., and Doxakis, E. (2014). miR-7 and miR-153 protect neurons against MPP(+)-induced cell death via upregulation of mTOR pathway. Front Cell Neurosci 8 , 182.

Fujii, R., and Takumi, T. (2005). TLS facilitates transport of mRNA encoding an actinstabilizing protein to dendritic spines. J Cell Sci $118,5755-5765$. 
Galeotti, N., and Ghelardini, C. (2011). Antidepressant phenotype by inhibiting the phospholipase Cbeta(1)--protein kinase Cgamma pathway in the forced swim test. Neuropharmacology 60, 937-943.

Ganley, I.G., Lam du, H., Wang, J., Ding, X., Chen, S., and Jiang, X. (2009).

ULK1.ATG13.FIP200 complex mediates mTOR signaling and is essential for autophagy. J Biol Chem 284, 12297-12305.

Gatt, J.M., Burton, K.L., Williams, L.M., and Schofield, P.R. (2015). Specific and common genes implicated across major mental disorders: a review of meta-analysis studies. J Psychiatr Res 60, 1-13.

Gideons, E.S., Kavalali, E.T., and Monteggia, L.M. (2014). Mechanisms underlying differential effectiveness of memantine and ketamine in rapid antidepressant responses. Proceedings of the National Academy of Sciences of the United States of America 111, 8649-8654.

Glasgow, N.G., Siegler Retchless, B., and Johnson, J.W. (2015). Molecular bases of NMDA receptor subtype-dependent properties. The Journal of physiology 593, 83-95. Goetze, B., Tuebing, F., Xie, Y., Dorostkar, M.M., Thomas, S., Pehl, U., Boehm, S., Macchi, P., and Kiebler, M.A. (2006). The brain-specific double-stranded RNA-binding protein Staufen2 is required for dendritic spine morphogenesis. J Cell Biol 172, 221 231.

Graber, T.E., McCamphill, P.K., and Sossin, W.S. (2013). A recollection of mTOR signaling in learning and memory. Learn Mem 20, 518-530. 
Gray, A.L., Hyde, T.M., Deep-Soboslay, A., Kleinman, J.E., and Sodhi, M.S. (2015). Sex differences in glutamate receptor gene expression in major depression and suicide. Mol Psychiatry 20, 1057-1068.

Gross, C., Nakamoto, M., Yao, X., Chan, C.B., Yim, S.Y., Ye, K., Warren, S.T., and Bassell, G.J. (2010). Excess phosphoinositide 3-kinase subunit synthesis and activity as a novel therapeutic target in fragile $\mathrm{X}$ syndrome. The Journal of neuroscience : the official journal of the Society for Neuroscience 30, 10624-10638.

Guetg, N., Abdel Aziz, S., Holbro, N., Turecek, R., Rose, T., Seddik, R., Gassmann, M., Moes, S., Jenoe, P., Oertner, T.G., et al. (2010). NMDA receptor-dependent GABAB receptor internalization via CaMKII phosphorylation of serine 867 in GABAB1.

Proceedings of the National Academy of Sciences of the United States of America 107, 13924-13929.

Hay, N., and Sonenberg, N. (2004). Upstream and downstream of mTOR. Genes Dev $18,1926-1945$.

Ibrahim, L., Diazgranados, N., Luckenbaugh, D.A., Machado-Vieira, R., Baumann, J., Mallinger, A.G., and Zarate, C.A., Jr. Rapid decrease in depressive symptoms with an $\mathrm{N}$-methyl-d-aspartate antagonist in ECT-resistant major depression. Prog Neuropsychopharmacol Biol Psychiatry 35, 1155-1159.

Jembrek, M.J., and Vlainic, J. (2015). GABA Receptors: Pharmacological Potential and Pitfalls. Curr Pharm Des 21, 4943-4959.

Jernigan, C.S., Goswami, D.B., Austin, M.C., Iyo, A.H., Chandran, A., Stockmeier, C.A., and Karolewicz, B. (2011). The mTOR signaling pathway in the prefrontal cortex is 
compromised in major depressive disorder. Prog Neuropsychopharmacol Biol

Psychiatry 35, 1774-1779.

Jia, J., and Le, W. (2015). Molecular network of neuronal autophagy in the pathophysiology and treatment of depression. Neurosci Bull 31, 427-434.

Jung, C.H., Jun, C.B., Ro, S.H., Kim, Y.M., Otto, N.M., Cao, J., Kundu, M., and Kim, D.H. (2009). ULK-Atg13-FIP200 complexes mediate mTOR signaling to the autophagy machinery. Mol Biol Cell 20, 1992-2003.

Kavalali, E.T., and Monteggia, L.M. (2012). Synaptic mechanisms underlying rapid antidepressant action of ketamine. Am J Psychiatry 169, 1150-1156.

Kavalali, E.T., and Monteggia, L.M. (2015). How does ketamine elicit a rapid antidepressant response? Curr Opin Pharmacol 20, 35-39.

Keck, T., Keller, G.B., Jacobsen, R.I., Eysel, U.T., Bonhoeffer, T., and Hubener, M. (2013). Synaptic scaling and homeostatic plasticity in the mouse visual cortex in vivo. Neuron 80, 327-334.

Keck, T., Scheuss, V., Jacobsen, R.I., Wierenga, C.J., Eysel, U.T., Bonhoeffer, T., and Hubener, M. (2011). Loss of sensory input causes rapid structural changes of inhibitory neurons in adult mouse visual cortex. Neuron 71, 869-882.

Kim, C.S., Chang, P.Y., and Johnston, D. (2012). Enhancement of dorsal hippocampal activity by knockdown of HCN1 channels leads to anxiolytic- and antidepressant-like behaviors. Neuron 75, 503-516.

Kirkwood, A., Rioult, M.C., and Bear, M.F. (1996). Experience-dependent modification of synaptic plasticity in visual cortex. Nature $381,526-528$. 
Kirov, S.A., and Harris, K.M. (1999). Dendrites are more spiny on mature hippocampal neurons when synapses are inactivated. Nature neuroscience 2, 878-883.

Kosten, T.A., Galloway, M.P., Duman, R.S., Russell, D.S., and D'Sa, C. (2008).

Repeated unpredictable stress and antidepressants differentially regulate expression of the bcl-2 family of apoptotic genes in rat cortical, hippocampal, and limbic brain structures. Neuropsychopharmacology 33, 1545-1558.

Krishnan, V., and Nestler, E.J. (2008). The molecular neurobiology of depression. Nature 455, 894-902.

Lee, E.J., and Tournier, C. (2011). The requirement of uncoordinated 51-like kinase 1 (ULK1) and ULK2 in the regulation of autophagy. Autophagy 7, 689-695.

Lee, M.C., Yasuda, R., and Ehlers, M.D. (2010a). Metaplasticity at single glutamatergic synapses. Neuron 66, 859-870.

Lee, S.Y., Hahn, C.Y., Lee, J.F., Huang, S.Y., Chen, S.L., Kuo, P.H., Lee, I.H., Yeh, T.L., Yang, Y.K., Chen, S.H., et al. (2010b). MAOA interacts with the ALDH2 gene in anxiety-depression alcohol dependence. Alcohol Clin Exp Res 34, 1212-1218.

Lepack, A.E., Fuchikami, M., Dwyer, J.M., Banasr, M., and Duman, R.S. (2015). BDNF release is required for the behavioral actions of ketamine. Int $\mathrm{J}$ Neuropsychopharmacol 18.

Li, N., Lee, B., Liu, R.J., Banasr, M., Dwyer, J.M., Iwata, M., Li, X.Y., Aghajanian, G., and Duman, R.S. (2010). mTOR-dependent synapse formation underlies the rapid antidepressant effects of NMDA antagonists. Science 329, 959-964.

Li, N., Liu, R.J., Dwyer, J.M., Banasr, M., Lee, B., Son, H., Li, X.Y., Aghajanian, G., and Duman, R.S. (2011). Glutamate N-methyl-D-aspartate receptor antagonists rapidly 
reverse behavioral and synaptic deficits caused by chronic stress exposure. Biol Psychiatry 69, 754-761.

Liu, R.J., Lee, F.S., Li, X.Y., Bambico, F., Duman, R.S., and Aghajanian, G.K. (2012). Brain-derived neurotrophic factor Val66Met allele impairs basal and ketaminestimulated synaptogenesis in prefrontal cortex. Biol Psychiatry 71, 996-1005. Liu, Z., Huang, L., Luo, X.J., Wu, L., and Li, M. (2015). MAOA Variants and Genetic Susceptibility to Major Psychiatric Disorders. Mol Neurobiol.

Lu, Y., Ferris, J., and Gao, F.B. (2009). Frontotemporal dementia and amyotrophic lateral sclerosis-associated disease protein TDP-43 promotes dendritic branching. Mol Brain 2, 30.

Luchelli, L., Thomas, M.G., and Boccaccio, G.L. (2015). Synaptic control of mRNA translation by reversible assembly of XRN1 bodies. J Cell Sci 128, 1542-1554.

Luo, K.R., Hong, C.J., Liou, Y.J., Hou, S.J., Huang, Y.H., and Tsai, S.J. (2010). Differential regulation of neurotrophin S100B and BDNF in two rat models of depression. Prog Neuropsychopharmacol Biol Psychiatry 34, 1433-1439.

Marino, G., Niso-Santano, M., Baehrecke, E.H., and Kroemer, G. (2014). Selfconsumption: the interplay of autophagy and apoptosis. Nat Rev Mol Cell Biol 15, 81 94.

McClung, C.A. (2007). Circadian genes, rhythms and the biology of mood disorders. Pharmacology \& therapeutics $114,222-232$.

McClung, C.A., and Nestler, E.J. (2008). Neuroplasticity mediated by altered gene expression. Neuropsychopharmacology 33, 3-17. 
McKernan, D.P., Dinan, T.G., and Cryan, J.F. (2009). "Killing the Blues": a role for cellular suicide (apoptosis) in depression and the antidepressant response? Prog Neurobiol 88, 246-263.

Megias, M., Emri, Z., Freund, T.F., and Gulyas, A.I. (2001). Total number and distribution of inhibitory and excitatory synapses on hippocampal CA1 pyramidal cells. Neuroscience 102, 527-540.

Miller, O.H., Yang, L., Wang, C.C., Hargroder, E.A., Zhang, Y., Delpire, E., and Hall, B.J. (2014). GluN2B-containing NMDA receptors regulate depression-like behavior and are critical for the rapid antidepressant actions of ketamine. eLife 3, e03581. Mukhopadhyay, S., Das, D.N., Panda, P.K., Sinha, N., Naik, P.P., Bissoyi, A., Pramanik, K., and Bhutia, S.K. (2015). Autophagy protein Ulk1 promotes mitochondrial apoptosis through reactive oxygen species. Free Radic Biol Med 89, 311-321. Murrough, J.W. (2012). Ketamine as a novel antidepressant: from synapse to behavior. Clin Pharmacol Ther 91, 303-309.

Murrough, J.W., and Charney, D.S. (2012). Is there anything really novel on the antidepressant horizon? Curr Psychiatry Rep 14, 643-649.

Niere, F., Namjoshi, S., Song, E., Dilly, G.A., Schoenhard, G., Zemelman, B.V., Mechref, Y., and Raab-Graham, K.F. (2015). Analysis of proteins that rapidly change upon mTORC1 repression identifies PARK7 as a novel protein aberrantly expressed in Tuberous Sclerosis Complex. Mol Cell Proteomics.

Niere, F., Namjoshi, S., Song, E., Dilly, G.A., Schoenhard, G., Zemelman, B.V., Mechref, Y., and Raab-Graham, K.F. (2016). Analysis of Proteins That Rapidly Change Upon Mechanistic/Mammalian Target of Rapamycin Complex 1 (mTORC1) Repression 
Identifies Parkinson Protein 7 (PARK7) as a Novel Protein Aberrantly Expressed in Tuberous Sclerosis Complex (TSC). Mol Cell Proteomics 15, 426-444.

Nosyreva, E., Szabla, K., Autry, A.E., Ryazanov, A.G., Monteggia, L.M., and Kavalali, E.T. (2013). Acute suppression of spontaneous neurotransmission drives synaptic potentiation. The Journal of neuroscience : the official journal of the Society for Neuroscience 33, 6990-7002.

Ogawa, S., and Kunugi, H. (2015). Inhibitors of Fatty Acid Amide Hydrolase and Monoacylglycerol Lipase: New Targets for Future Antidepressants. Curr Neuropharmacol 13, 760-775.

Ohgi, Y., Futamura, T., and Hashimoto, K. (2015). Glutamate Signaling in Synaptogenesis and NMDA Receptors as Potential Therapeutic Targets for Psychiatric Disorders. Current molecular medicine 15, 206-221.

Padgett, C.L., and Slesinger, P.A. GABAB receptor coupling to G-proteins and ion channels. Adv Pharmacol 58, 123-147.

Pei, J.J., and Hugon, J. (2008). mTOR-dependent signalling in Alzheimer's disease. Journal of cellular and molecular medicine 12, 2525-2532.

Philpot, B.D., Espinosa, J.S., and Bear, M.F. (2003). Evidence for altered NMDA receptor function as a basis for metaplasticity in visual cortex. The Journal of neuroscience : the official journal of the Society for Neuroscience 23, 5583-5588. Pittenger, C., and Duman, R.S. (2008). Stress, depression, and neuroplasticity: a convergence of mechanisms. Neuropsychopharmacology 33, 88-109.

Pozo, K., and Goda, Y. (2010). Unraveling mechanisms of homeostatic synaptic plasticity. Neuron 66, 337-351. 
Queenan, B.N., Lee, K.J., and Pak, D.T. (2012). Wherefore art thou, homeo(stasis)? Functional diversity in homeostatic synaptic plasticity. Neural plasticity 2012, 718203. Raab-Graham, K.F., Haddick, P.C., Jan, Y.N., and Jan, L.Y. (2006). Activity- and mTOR-dependent suppression of Kv1.1 channel mRNA translation in dendrites. Science 314, 144-148.

Ray, M.T., Shannon Weickert, C., and Webster, M.J. (2014). Decreased BDNF and TrkB mRNA expression in multiple cortical areas of patients with schizophrenia and mood disorders. Transl Psychiatry 4, e389.

Reese, A.L., and Kavalali, E.T. (2015). Spontaneous neurotransmission signals through store-driven $\mathrm{Ca}(2+)$ transients to maintain synaptic homeostasis. Elife 4.

Rietschel, M., Mattheisen, M., Frank, J., Treutlein, J., Degenhardt, F., Breuer, R., Steffens, M., Mier, D., Esslinger, C., Walter, H., et al. (2010). Genome-wide association, replication-, and neuroimaging study implicates HOMER1 in the etiology of major depression. Biol Psychiatry 68, 578-585.

Rush, A.J., Trivedi, M.H., Wisniewski, S.R., Nierenberg, A.A., Stewart, J.W., Warden, D., Niederehe, G., Thase, M.E., Lavori, P.W., Lebowitz, B.D., et al. (2006). Acute and longer-term outcomes in depressed outpatients requiring one or several treatment steps: a STAR*D report. The American journal of psychiatry $163,1905-1917$. Sadasivan, S., Zhang, Z., Larner, S.F., Liu, M.C., Zheng, W., Kobeissy, F.H., Hayes, R.L., and Wang, K.K. (2010). Acute NMDA toxicity in cultured rat cerebellar granule neurons is accompanied by autophagy induction and late onset autophagic cell death phenotype. BMC Neurosci 11, 21. 
Sahin, M. (2012). Targeted treatment trials for tuberous sclerosis and autism: no longer a dream. Current opinion in neurobiology 22, 895-901.

Sakaida, M., Sukeno, M., Imoto, Y., Tsuchiya, S., Sugimoto, Y., Okuno, Y., and SegiNishida, E. (2013). Electroconvulsive seizure-induced changes in gene expression in the mouse hypothalamic paraventricular nucleus. J Psychopharmacol 27, 1058-1069. Santini, E., and Klann, E. (2011). Dysregulated mTORC1-Dependent Translational Control: From Brain Disorders to Psychoactive Drugs. Frontiers in behavioral neuroscience 5,76 .

Sephton, C.F., Tang, A.A., Kulkarni, A., West, J., Brooks, M., Stubblefield, J.J., Liu, Y., Zhang, M.Q., Green, C.B., Huber, K.M., et al. (2014). Activity-dependent FUS dysregulation disrupts synaptic homeostasis. Proc Natl Acad Sci U S A 111, E47694778.

Serchov, T., Heumann, R., Calker, D.V., and Biber, K. (2015). Signaling pathways regulating Homer1a expression: implications for antidepressant therapy. Biol Chem. Sharma, A., Hoeffer, C.A., Takayasu, Y., Miyawaki, T., McBride, S.M., Klann, E., and Zukin, R.S. (2010). Dysregulation of mTOR signaling in fragile X syndrome. The Journal of neuroscience : the official journal of the Society for Neuroscience 30,694-702. Shelton, R.C., Claiborne, J., Sidoryk-Wegrzynowicz, M., Reddy, R., Aschner, M., Lewis, D.A., and Mirnics, K. (2011). Altered expression of genes involved in inflammation and apoptosis in frontal cortex in major depression. Mol Psychiatry 16, 751-762.

Shyn, S.I., Shi, J., Kraft, J.B., Potash, J.B., Knowles, J.A., Weissman, M.M., Garriock, H.A., Yokoyama, J.S., McGrath, P.J., Peters, E.J., et al. (2011). Novel loci for major depression identified by genome-wide association study of Sequenced Treatment 
Alternatives to Relieve Depression and meta-analysis of three studies. Mol Psychiatry $16,202-215$.

Skolnick, P., Popik, P., and Trullas, R. (2009). Glutamate-based antidepressants: 20 years on. Trends in pharmacological sciences $30,563-569$.

Skoog, I., Waern, M., Duberstein, P., Blennow, K., Zetterberg, H., Borjesson-Hanson, A., Ostling, S., Guo, X., Kern, J., Gustafson, D., et al. (2015). A 9-Year Prospective Population-Based Study on the Association Between the APOE*E4 Allele and Late-Life Depression in Sweden. Biol Psychiatry 78, 730-736.

Sobczyk, A., Scheuss, V., and Svoboda, K. (2005). NMDA receptor subunit-dependent [Ca2+] signaling in individual hippocampal dendritic spines. The Journal of neuroscience : the official journal of the Society for Neuroscience 25, 6037-6046. Soden, M.E., and Chen, L. (2010). Fragile X protein FMRP is required for homeostatic plasticity and regulation of synaptic strength by retinoic acid. The Journal of neuroscience : the official journal of the Society for Neuroscience 30,16910-16921. Sosanya, N.M., Brager, D.H., Wolfe, S., Niere, F., and Raab-Graham, K.F. (2014). Rapamycin reveals an mTOR-independent Repression of Kv1.1 Expression during Epileptogenesis. Neurobiology of disease.

Sosanya, N.M., Brager, D.H., Wolfe, S., Niere, F., and Raab-Graham, K.F. (2015a). Rapamycin reveals an mTOR-independent repression of Kv1.1 expression during epileptogenesis. Neurobiol Dis 73, 96-105.

Sosanya, N.M., Cacheaux, L.P., Workman, E.R., Niere, F., Perrone-Bizzozero, N.I., and Raab-Graham, K.F. (2015b). Mammalian Target of Rapamycin (mTOR) Tagging Promotes Dendritic Branch Variability through the Capture of $\mathrm{Ca} 2+/$ Calmodulin- 
dependent Protein Kinase II alpha (CaMKIlalpha) mRNAs by the RNA-binding Protein HuD. J Biol Chem 290, 16357-16371.

Sosanya, N.M., Huang, P.P., Cacheaux, L.P., Chen, C.J., Nguyen, K., Perrone-

Bizzozero, N.I., and Raab-Graham, K.F. (2013). Degradation of high affinity HuD targets releases Kv1.1 mRNA from miR-129 repression by mTORC1. J Cell Biol 202, 53-69. Spilman, P., Podlutskaya, N., Hart, M.J., Debnath, J., Gorostiza, O., Bredesen, D., Richardson, A., Strong, R., and Galvan, V. (2010). Inhibition of mTOR by rapamycin abolishes cognitive deficits and reduces amyloid-beta levels in a mouse model of Alzheimer's disease. PloS one 5, e9979.

Stachowicz, A., Glombik, K., Olszanecki, R., Basta-Kaim, A., Suski, M., Lason, W., and Korbut, R. (2015). The impact of mitochondrial aldehyde dehydrogenase (ALDH2) activation by Alda-1 on the behavioral and biochemical disturbances in animal model of depression. Brain Behav Immun.

Sutton, M.A., Ito, H.T., Cressy, P., Kempf, C., Woo, J.C., and Schuman, E.M. (2006). Miniature neurotransmission stabilizes synaptic function via tonic suppression of local dendritic protein synthesis. Cell 125, 785-799.

Sutton, M.A., and Schuman, E.M. (2006). Dendritic protein synthesis, synaptic plasticity, and memory. Cell 127, 49-58.

Sutton, M.A., Wall, N.R., Aakalu, G.N., and Schuman, E.M. (2004). Regulation of dendritic protein synthesis by miniature synaptic events. Science 304, 1979-1983.

Szumlinski, K.K., Lominac, K.D., Kleschen, M.J., Oleson, E.B., Dehoff, M.H., Schwarz, M.K., Seeburg, P.H., Worley, P.F., and Kalivas, P.W. (2005). Behavioral and 
neurochemical phenotyping of Homer1 mutant mice: possible relevance to schizophrenia. Genes, brain, and behavior 4, 273-288.

Tadic, A., Rujescu, D., Muller, M.J., Kohnen, R., Stassen, H.H., Dahmen, N., and Szegedi, A. (2007). A monoamine oxidase B gene variant and short-term antidepressant treatment response. Prog Neuropsychopharmacol Biol Psychiatry 31, 1370-1377.

Takei, N., Inamura, N., Kawamura, M., Namba, H., Hara, K., Yonezawa, K., and Nawa, H. (2004). Brain-derived neurotrophic factor induces mammalian target of rapamycindependent local activation of translation machinery and protein synthesis in neuronal dendrites. The Journal of neuroscience : the official journal of the Society for Neuroscience 24, 9760-9769.

Tang, S.J., Meulemans, D., Vazquez, L., Colaco, N., and Schuman, E. (2001). A role for a rat homolog of staufen in the transport of RNA to neuronal dendrites. Neuron 32, 463475.

Tavazoie, S.F., Alvarez, V.A., Ridenour, D.A., Kwiatkowski, D.J., and Sabatini, B.L. (2005). Regulation of neuronal morphology and function by the tumor suppressors Tsc1 and Tsc2. Nature neuroscience 8, 1727-1734.

Terunuma, M., Vargas, K.J., Wilkins, M.E., Ramirez, O.A., Jaureguiberry-Bravo, M., Pangalos, M.N., Smart, T.G., Moss, S.J., and Couve, A. (2010). Prolonged activation of NMDA receptors promotes dephosphorylation and alters postendocytic sorting of GABAB receptors. Proceedings of the National Academy of Sciences of the United States of America 107, 13918-13923. 
Thomas, M.G., Pascual, M.L., Maschi, D., Luchelli, L., and Boccaccio, G.L. (2014). Synaptic control of local translation: the plot thickens with new characters. Cell Mol Life Sci 71, 2219-2239.

Trivedi, M.H., Hollander, E., Nutt, D., and Blier, P. (2008). Clinical evidence and potential neurobiological underpinnings of unresolved symptoms of depression. The Journal of clinical psychiatry 69, 246-258.

Trivedi, M.H., Rush, A.J., Wisniewski, S.R., Nierenberg, A.A., Warden, D., Ritz, L., Norquist, G., Howland, R.H., Lebowitz, B., McGrath, P.J., et al. (2006). Evaluation of outcomes with citalopram for depression using measurement-based care in STAR* $D$ : implications for clinical practice. The American journal of psychiatry $163,28-40$. Turrigiano, G. (2012). Homeostatic synaptic plasticity: local and global mechanisms for stabilizing neuronal function. Cold Spring Harbor perspectives in biology 4, a005736. Turrigiano, G.G. (2008). The self-tuning neuron: synaptic scaling of excitatory synapses. Cell 135, 422-435.

Turrigiano, G.G., and Nelson, S.B. (2000). Hebb and homeostasis in neuronal plasticity. Curr Opin Neurobiol 10, 358-364.

Unschuld, P.G., Ising, M., Specht, M., Erhardt, A., Ripke, S., Heck, A., Kloiber, S., Straub, V., Brueckl, T., Muller-Myhsok, B., et al. (2009). Polymorphisms in the GAD2 gene-region are associated with susceptibility for unipolar depression and with a risk factor for anxiety disorders. Am J Med Genet B Neuropsychiatr Genet 150B, 11001109.

Wagner, K.V., Hartmann, J., Labermaier, C., Hausl, A.S., Zhao, G., Harbich, D., Schmid, B., Wang, X.D., Santarelli, S., Kohl, C., et al. (2015). Homer1/mGluR5 activity 
moderates vulnerability to chronic social stress. Neuropsychopharmacology $40,1222-$ 1233.

Wallace, W., and Bear, M.F. (2004). A morphological correlate of synaptic scaling in visual cortex. The Journal of neuroscience : the official journal of the Society for Neuroscience 24, 6928-6938.

Workman, E.R., Haddick, P.C., Bush, K., Dilly, G.A., Niere, F., Zemelman, B.V., and Raab-Graham, K.F. (2015). Rapid antidepressants stimulate the decoupling of GABA receptors from GIRK/Kir3 channels through increased protein stability of 14-3-3eta. Molecular psychiatry.

Workman, E.R., Niere, F., and Raab-Graham, K.F. (2013). mTORC1-dependent protein synthesis underlying rapid antidepressant effect requires GABABR signaling. Neuropharmacology 73, 192-203.

Xin, X.Y., Pan, J., Wang, X.Q., Ma, J.F., Ding, J.Q., Yang, G.Y., and Chen, S.D. (2011). 2-methoxyestradiol attenuates autophagy activation after global ischemia. Can J Neurol Sci 38, 631-638.

Yashiro, K., and Philpot, B.D. (2008). Regulation of NMDA receptor subunit expression and its implications for LTD, LTP, and metaplasticity. Neuropharmacology 55, 10811094.

Yin, J., and Yuan, Q. (2014). Structural homeostasis in the nervous system: a balancing act for wiring plasticity and stability. Frontiers in cellular neuroscience 8, 439.

Yoshimasu, K., Mure, K., Hashimoto, M., Takemura, S., Tsuno, K., Hayashida, M., Kinoshita, K., Takeshita, T., and Miyashita, K. (2015). Genetic alcohol sensitivity 
regulated by $\mathrm{ALDH} 2$ and $\mathrm{ADH} 1 \mathrm{~B}$ polymorphisms is strongly associated with depression and anxiety in Japanese employees. Drug Alcohol Depend 147, 130-136.

Zarate, C., Duman, R.S., Liu, G., Sartori, S., Quiroz, J., and Murck, H. (2013). New paradigms for treatment-resistant depression. Ann N Y Acad Sci 1292, 21-31.

Zarate, C., Jr., Machado-Vieira, R., Henter, I., Ibrahim, L., Diazgranados, N., and

Salvadore, G. (2010). Glutamatergic modulators: the future of treating mood disorders? Harv Rev Psychiatry 18, 293-303.

Zarate, C.A., Jr., Singh, J.B., Carlson, P.J., Brutsche, N.E., Ameli, R., Luckenbaugh, D.A., Charney, D.S., and Manji, H.K. (2006). A randomized trial of an N-methyl-Daspartate antagonist in treatment-resistant major depression. Arch Gen Psychiatry 63, 856-864.

Zeng, L.H., Rensing, N.R., and Wong, M. (2009). The mammalian target of rapamycin signaling pathway mediates epileptogenesis in a model of temporal lobe epilepsy. The Journal of neuroscience : the official journal of the Society for Neuroscience 29,69646972.

Zeng, L.H., Rensing, N.R., Zhang, B., Gutmann, D.H., Gambello, M.J., and Wong, M. (2011). Tsc2 gene inactivation causes a more severe epilepsy phenotype than Tsc1 inactivation in a mouse model of tuberous sclerosis complex. Human molecular genetics 20, 445-454.

Zuo, Y., Yang, G., Kwon, E., and Gan, W.B. (2005). Long-term sensory deprivation prevents dendritic spine loss in primary somatosensory cortex. Nature 436, 261-265. 


\section{Figure Legends}

Figure 1: Model for rapid antidepressant activation of homeostatic mechanisms.

(A) MDD leads to a network that is outside of the ideal homeostatic range, as indicated by the out of balance scale. (B) NMDAR antagonists (green circle) pushes the network further outside the ideal range activating homeostatic mechanisms $(C)$ that result in relief from MDD and remission (D).

Figure 2: Cartoon describing molecular pathways triggered by NMDAR antagonists. (left panel) Activation of GABABRs signal to open GIRK channels reducing dendritic calcium levels. Calcium entry through NMDARs activates the translation elongation factor kinase eEF2K that in turn phosphorylates eEF2, inhibiting global translation. (right panel) In the presence of NMDAR antagonists $G A B A_{B} R$ signaling shift to facilitating L-type calcium channel activity and activates mTOR-dependent protein synthesis. This requires the protein synthesis and insertion of new $\mathrm{GABA}_{B} R$ s into the dendritic membrane. What RNA binding protein (RBP) mediates $G A B A_{B} R$ mRNA repression (left) and or translation (right) is an open question. In addition, Reduced NMDAR signaling to eEF2K increases the activity of eEF2 allowing for global translation. eEF2 protein expression increases when mTOR activity is reduced. If new eEF2 mRNA translation and the RBPs that regulate its expression is unknown.

Figure 3: Protein expression regulated by mTORC1 activity overlap with depression. (A) Venn diagram illustrating several proteins identified by mass spectrometry of synapses with brief in vivo mTORC1 inhibition overlap with proteins 
associated with depression. (B) Heat map of 16 overlapping proteins in the postsynaptic density fraction $(\mathrm{P})$ and soluble fraction $(\mathrm{S})$ of synaptoneurosomes isolated from cortices of control and rapamycin injected rats. Note, many of those proteins increase with mTORC1 inhibition (yellow). (C) Heat map of EEF2, demonstrating increased expression in soluble fraction of synaptoneurosomes with brief mTORC1 inhibition. Data obtained from Niere et al., 2015 and (Aragam et al., 2011; De Vry et al., 2016; Dekker et al., 2012; Dlugos et al., 2009; Fatemi et al., 2001; Galeotti and Ghelardini, 2011; Gatt et al., 2015; Gray et al., 2015; Lee et al., 2010b; Liu et al., 2015; Luo et al., 2010; Ogawa and Kunugi, 2015; Ray et al., 2014; Rietschel et al., 2010; Sakaida et al., 2013; Shyn et al., 2011; Skoog et al., 2015; Stachowicz et al., 2015; Tadic et al., 2007; Unschuld et al., 2009; Wagner et al., 2015; Yoshimasu et al., 2015) for bioinformatics analysis. 
A.

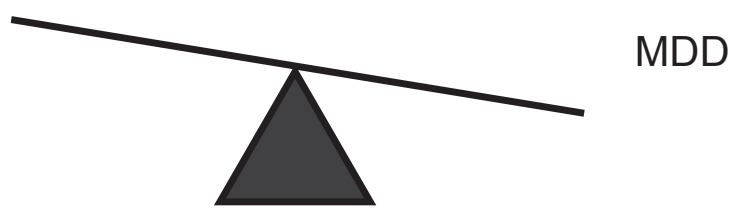

B.

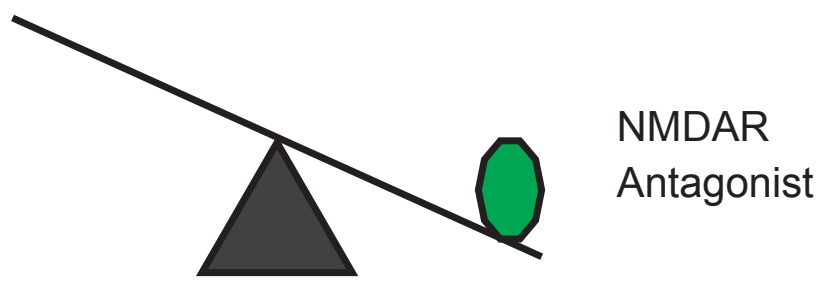

C.

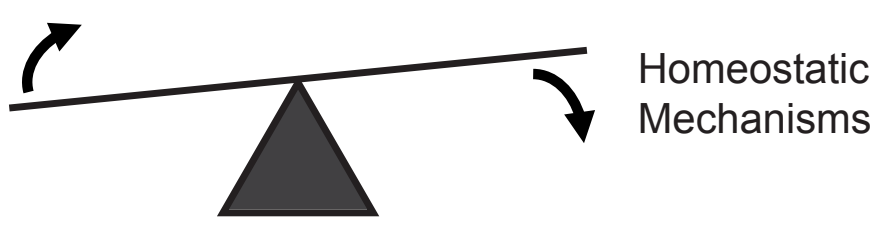

D.

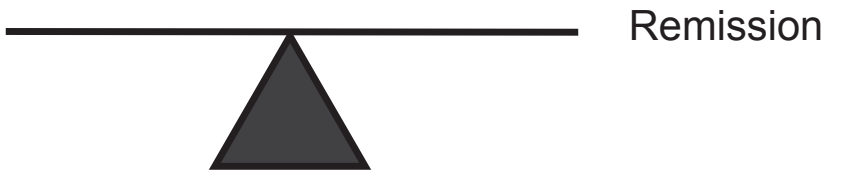


Normal Conditions

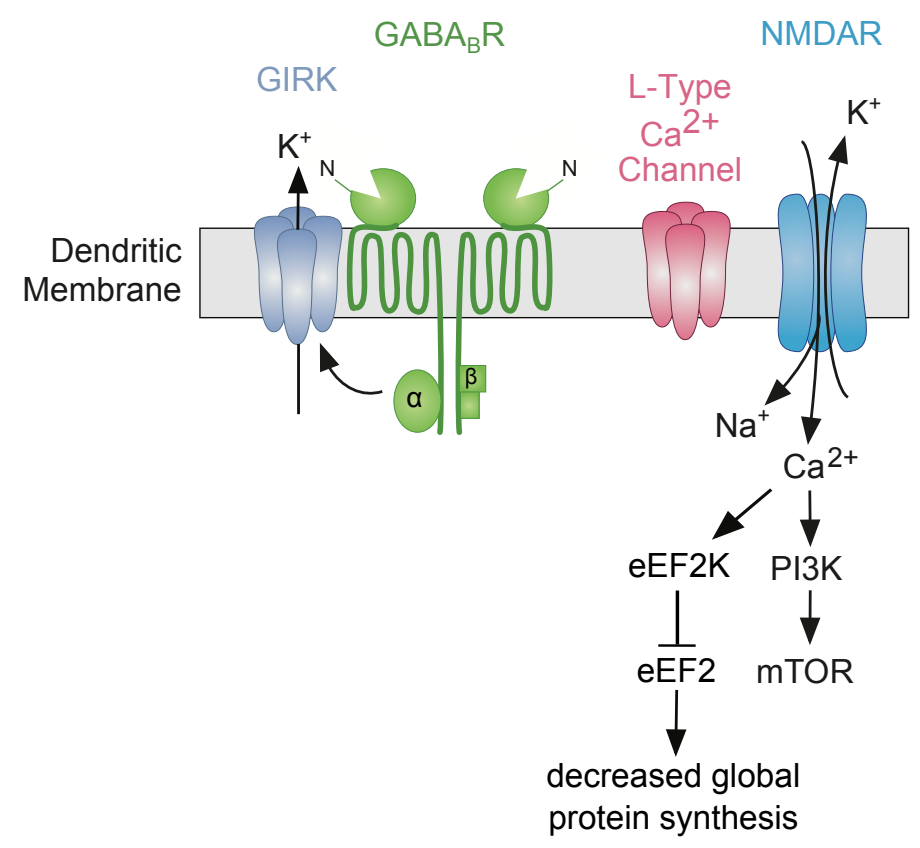

NMDAR Antagonism

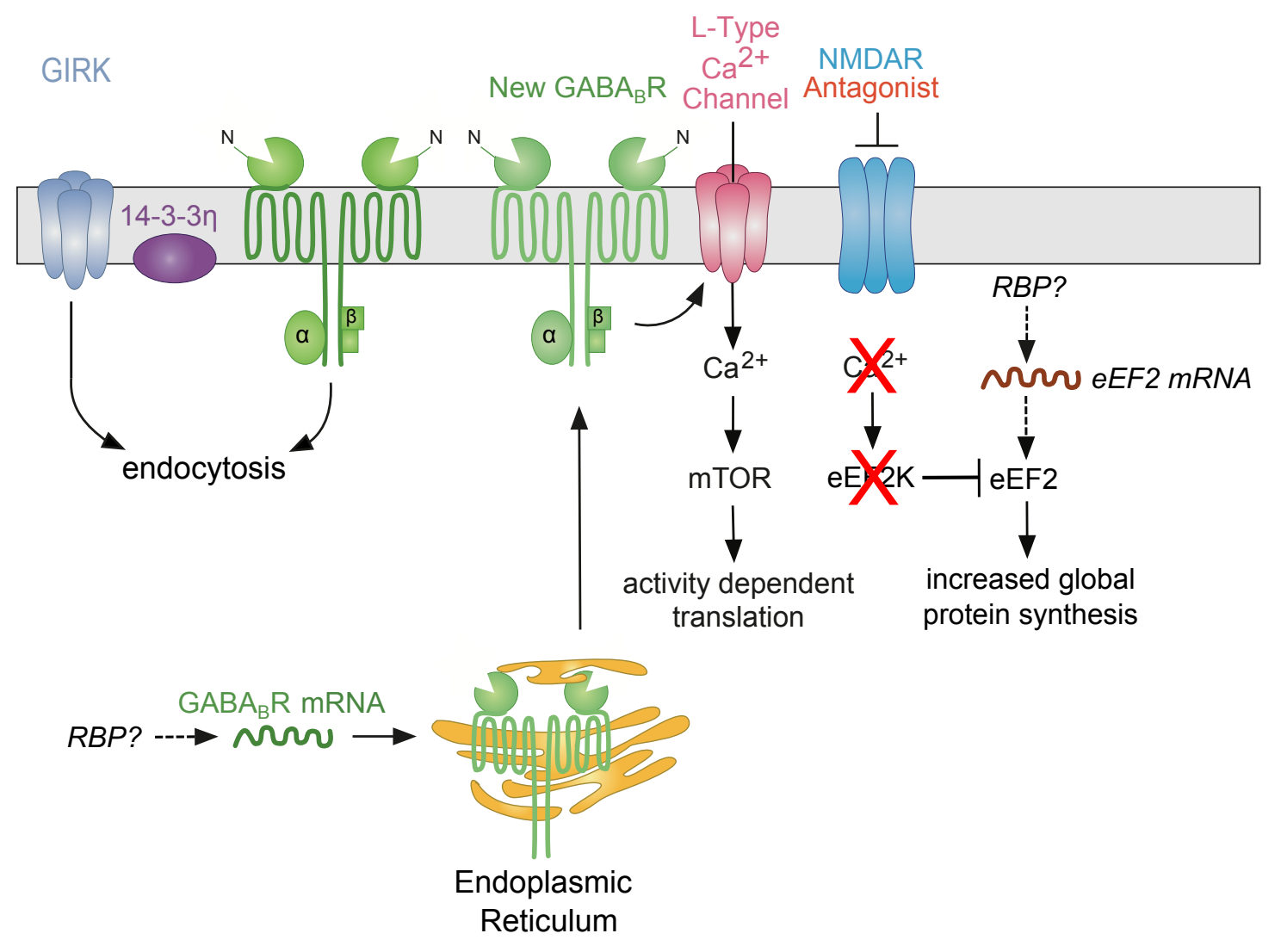




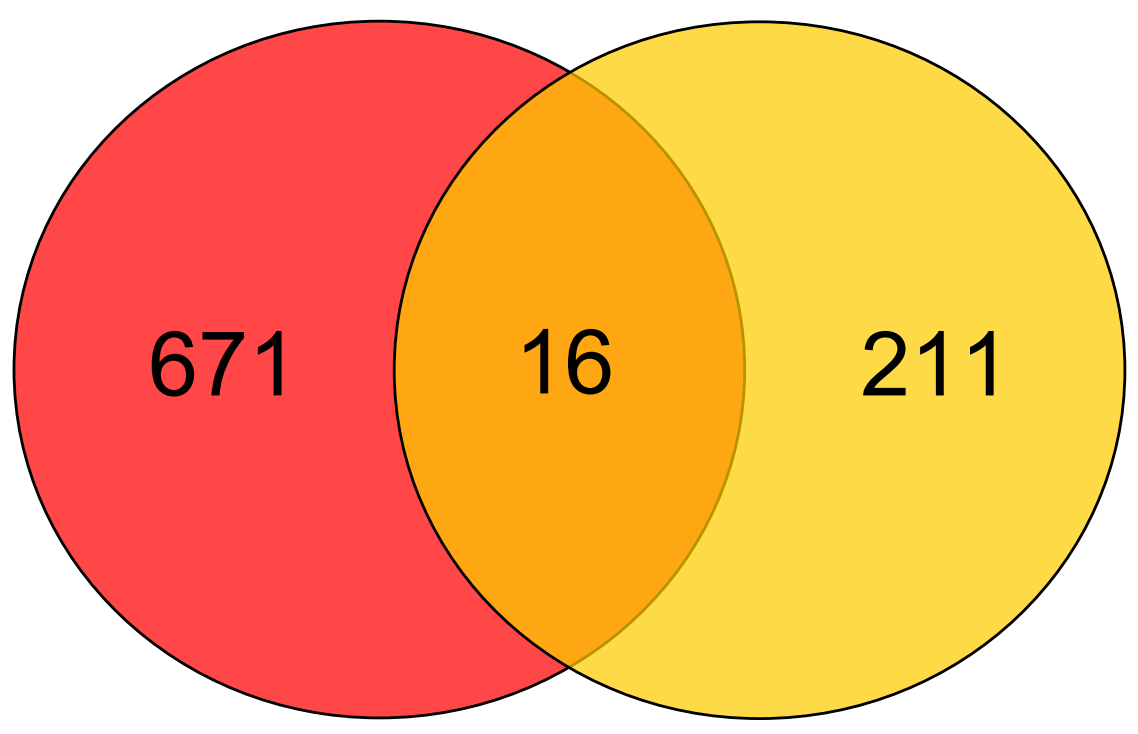

Mass Spectrometry Data

Candidate Major

Depressive Disorder Genes
ALDH2 APOE ATP6V1B2 FAAH GAD2 GRIN1 HOMER1 HSD11B1 MAOA MAOB NTRK2 PCLO PRKCB PRKCG S100B SNAP25
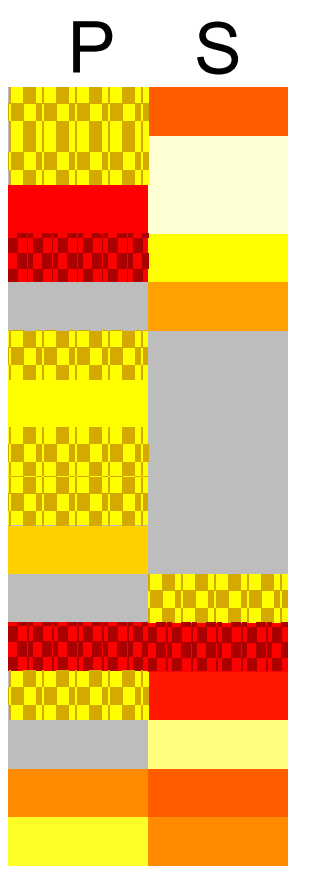

C.

eEF2

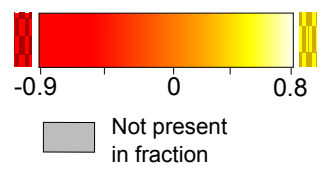


Table 1. Homeostatic Response to NMDAR antagonism

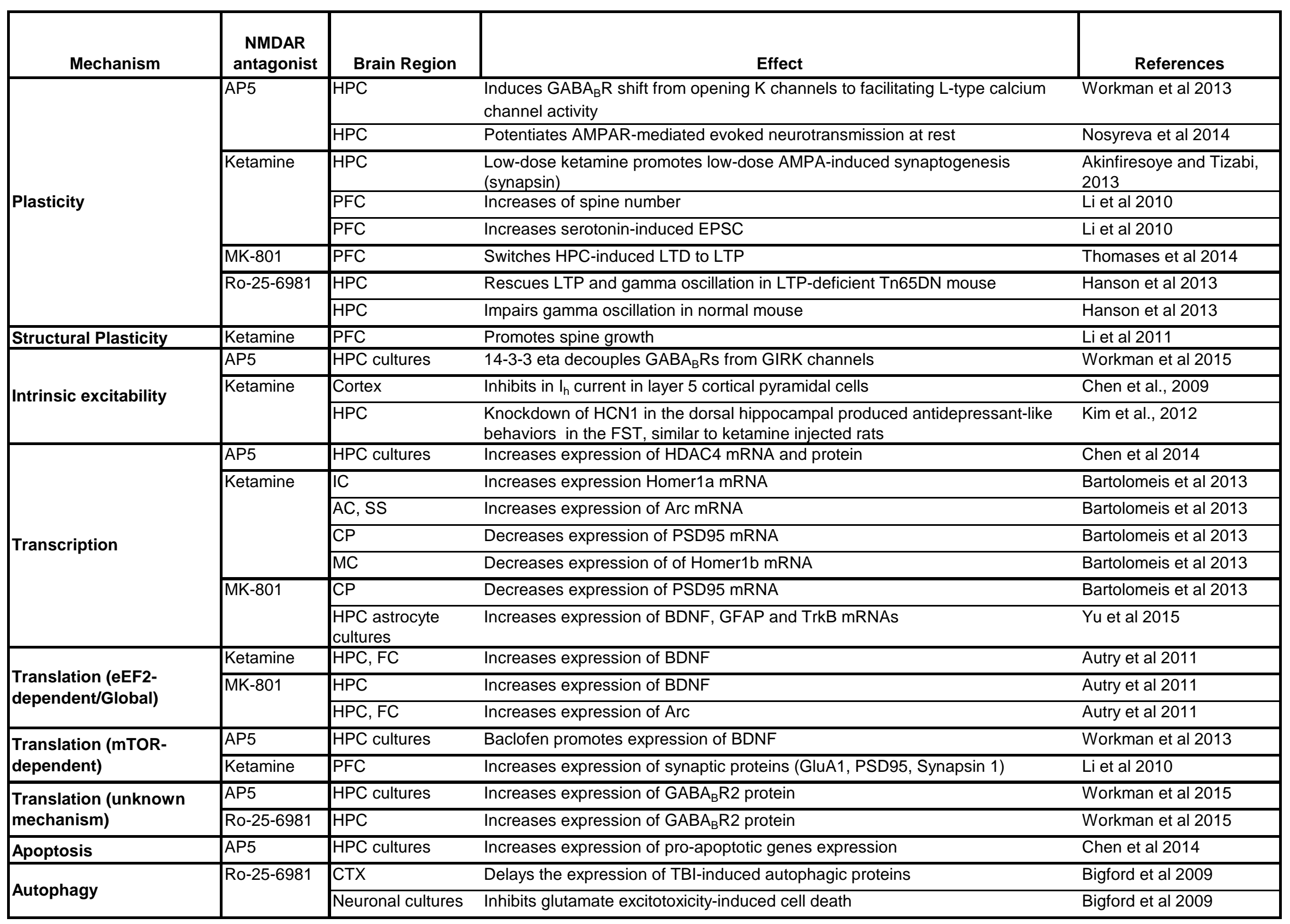

